\title{
Posibilidades del autorretrato fotográfico como herramienta terapéutica en mujeres víctimas de violencia de género: experiencia de un taller
}

\author{
Alejandra ZOLEZZI VERA ${ }^{1}$ \\ Universidad Católica de Chile \\ alezolezzi@gmail.com
}

Recibido: $31 / 03 / 13$

Aceptado: 09/12/13

\begin{abstract}
RESUMEN
Este artículo relata y reflexiona en torno a la experiencia del proyecto "Derecho a la Mirada y Creación Propias: Taller de Autorretrato e Identidad para la Mujer”. Dicho proyecto se llevó a cabo en Valdivia, Chile, y se dirigió a mujeres víctimas de violencia de género. Se trabajaron las temáticas del cuerpo y la conciencia corporal, y de la expresión y la creatividad, culminando en el proceso de creación, toma fotográfica y exposición de autorretratos. Como resultados, pudimos ver cambios positivos en el autoestima y el autoconcepto, creación de redes de apoyo, y, en general, afirmaciones de un mayor bienestar y felicidad personales.
\end{abstract}

Palabras clave: arteterapia, autorretrato fotográfico, escritura creativa, violencia de género, autoconciencia corporal.

\section{Referencia normalizada}

ZOLEZZI VERA, A. (2013). "Posibilidades del autorretrato fotográfico como herramienta terapéutica en mujeres víctimas de violencia de género: experiencia de un taller". En Arteterapia: Papeles de arteterapia y educación artística para la inclusión social Vol.: 8. Páginas 45-60.

\section{SUMARIO}

Las huellas de la violencia. El cuerpo violentado. Terapia a través del arte. Derecho a la mirada y creación propias: el proyecto. El camino hacia los autorretratos. Taller de autoconciencia corporal. Expresión a través de la poesía. Desarrollo de la experiencia: el grupo como red de apoyo y el proceso creativo. Autorretratos y exposición. Algunos testimonios. Conclusiones.

\footnotetext{
${ }^{1}$ Psicóloga de la Universidad Católica de Chile con un máster en Documental Creativo en la Universidad Autónoma de Barcelona.
} 


\title{
Prospects of photographic self-portrait as a therapeutical aid for women victims of gender violence: a workshop's experience
}

\begin{abstract}
This article reviews and analyses the experience of the project "Right to See and Create Myself: a Self-Portrait and Identity Workshop for Women". This project was executed in Valdivia, Chile, and focused on women victims of gender-based violence. Together, we worked issues as their bodies and self-conscience, intertwined with expression and creativity, process which lead to the creation and exposition of self-portraits. As some results, we could appreciate visible changes in self-esteem and self-concept, the foundation of support networks within the group, and positive statements concerning happiness and a better well-being.
\end{abstract}

Keywords: art therapy, photographic self-portrait, creative writing, gender violence, body selfconscience.

\section{CONTENTS}

The tracks of violence. Violence in the body. Therapy through art. Right to see and create myself: the project. The way to self-portraits. Corporal self-conscience workshop. Expression throughpoetry. Project's experience: the group as support network and the creative process. Self-portraits and exhibition. Some testimonies. Findings.

\section{p}

Hoy, la violencia hacia las mujeres es reconocida públicamente como una problemática social de alto impacto, tanto en Chile como en el mundo entero. El taller "Derecho a la Mirada y Creación Propias" fue propuestofrente a esta problemática y apuntó principalmente a actuar en el proceso de reparación emocional de mujeres víctimas de violencia de género a través de dinámicas creativas y de expresión que desembocaran en una nueva mirada hacia sí mismas a través del autorretrato.

La experiencia de este taller surge ante la iniciativa de la fotógrafa chilena Victoria Soto, cuyo interés primordial se enfoca en la capacidad curativa del autorretrato y sus posibilidades como complemento terapéutico en el tema de la violencia de género. De esta manera, se contacta con Maha Vial, poeta, dramaturga y actriz, y conmigo, psicóloga, terapeuta corporal e instructora de Yoga. A partir de este encuentro de caminos, comenzamos esta experiencia que creemos contribuyó a cambiar algunas vidas, y fue el inicio de un proyecto artísticoterapéutico que pretende continuar aportando a las vidas de mujeres víctimas de violencia de género. 


\section{LAS HUELLAS DE LA VIOLENCIA}

Se ha hablado mucho acerca de violencia intrafamiliar y, especialmente durante este último tiempo, de violencia de género. Aun así, y debido a la importancia de aludir a este tema en un artículo como éste, me referiré brevemente a este concepto para contextualizar adecuadamente nuestro trabajo en este taller.

La Violencia de Género es definida por la ONU como:

Todo acto de violencia basado en el género que tiene como resultado posible o real un daño físico, sexual o psicológico, incluidas las amenazas, la coerción o la privación arbitraria de la libertad, ya sea que ocurra en la vida pública o privada.

(Alto Comisionado de las Naciones Unidas para los Derechos Humanos, 2000, p.2)

De esta manera, es posible situar la violencia de género dentro del contexto de la sociedad patriarcal que impera actualmente y en la que se observa un modelo de dominación del hombre por sobre la mujeres donde la violencia física aparece como una más de sus manifestaciones.

Uno de los grandes problemas de este tipo de violencia es que genera un ciclo del cual es muy difícil para la víctima escapar. Walker (1979, citado en Gil Rodríguez \& Lloret Ayter, 2007) describe este ciclo de la violencia dividiéndolo en tres etapas. En la primera se acumula tensión en la pareja, en la segunda explota esta tensión produciéndose el episodio agudo de manifestación de la violencia, y en la tercera fase se produciría la reconciliación o luna de miel, en la cual el maltratador promete no volver a hacerlo, se justifica de diversas maneras (incluso culpando a la mujer, argumentando, por ejemplo, que es ella la que lo lleva a comportarse de esa manera) y, durante un tiempo, remite la violencia (hasta que se acumula nuevamente tensión, se produce el episodio agudo y se vuelve a la reconciliación, y así indefinidamente).

A la complejidad de lo mencionado anteriormente, se suma la conducta ambivalente de la mujer violentada: idas del hogar y denuncias se alternan con vueltas al hogar y retiro de denuncias. Esta ambivalencia es fácilmente comprensible al considerar el miedo y la vulnerabilidad de las víctimas, las diversas presiones familiares y del entorno y el temor a no poder salir adelante solas. Entonces, para resistir la violencia en la relación, la mujer acaba sometiéndose para no desencadenar la ira en la pareja. (Gil Rodríguez \& Lloret Ayter, 2007)

$\mathrm{La}$ violencia por parte del hombre hacia la mujer se manifiesta de diversas formas, pero en todas ellas se hace evidente el hecho que se enmarca en un contexto de "relaciones de poder" que ha devenido en "relaciones de dominación", en el decir de Foucault. La parte dominada "no puede invertir los términos de la relación, ya que esta subversión amenazaría su existencia" (Gil Rodríguez \& Lloret Ayter, 2007, p. 36). Debido a que la amplitud de estas manifestaciones incluye desde el maltrato físico hasta el social, pasando por el sexual, económico 
y emocional, entre otros, las consecuencias de dichos actos repercutirán en diferentes ámbitos y aspectos de la mujer. De esta manera, al enfocarnos en el ámbito personal, observamos que estos efectos incluyen la salud física, sexualreproductiva, mental-emocional y social. La profundidad de los efectos de la violencia dependerán del tipo, duración, intensidad y significación por parte de la mujer a esta violencia recibida. Entre las consecuencias más comunes podemos observar miedo, desasosiego, inseguridad, vergüenza, vulnerabilidad e indefensión, lo que se relaciona con una marcada disminución en la autoestima y autoconfianza. Además, debemos recordar que como la violencia se percibe como proveniente de un ser con el que se tiene un vínculo afectivo, el dolor y los efectos mencionados seránaun más profundos (Gil Rodríguez\& Lloret Ayter, 2007).

\section{EL CUERPO VIOLENTADO}

La subjetividad de las mujeres, de acuerdo a las construcciones de género, queda impregnada del ser-para-otros y satisfacer las demandas emocionales de otros, alejándose progresivamente del contacto consigo mismas, del registro de lo que ocurre en sus emociones y en sus cuerpos, negando y anestesiando los propios signos y malestares. (Machuca, 2001, p. 26)

Socialmente, se espera que la mujer se sacrifique frente al hogar y la familia, y que sean éstas sus prioridades incondicionales. Estas expectativas alejan a las mujeres de ellas mismas, enfermándolas mental y físicamente, y con consecuencias como estrés, infelicidad, baja autoestima, etc.Lowen (2010) afirma que toda experiencia estresante crea tensión en el cuerpo. En un proceso normal, la tensión desaparece al desaparecer el estresor, pero cuando el estrés permanece por largos periodos de tiempo (como es en el caso de la violencia en el hogar), la tensión se hace crónica. Entonces, aun cuando posteriormente desaparezca el factor estresante, la tensión muscular continúa bajo la forma de una actitud inconsciente del cuerpo o de un grupo de músculos. Estas tensiones no sólo restringen nuestra movilidad y expresión corporal, sino que también perturban nuestra salud emocional y disminuyen nuestra energía. De esta manera, se hace necesario aliviar estas tensiones para recuperar la salud y el bienestar físico y psíquico. Asimismo, las inhibiciones del llanto y el grito causan tensiones musculares que restringen la respiración, lo que, para Lowen (2010), tiene graves consecuencias ya que estar plenamente vivo es respirar profundamente, moverse libremente y sentir plenamente.

Podemos, de esta manera, intuir cómo los cuerpos de estas mujeres maltratadas se encuentran contraídos y adoloridos, con sus movimientos restringidos y coartados, al igual que sus mentes y emociones. Entonces, se hace insuficiente la palabra y necesario el movimiento para una liberación del cuerpo que acompañe la liberación de la mente y emociones. 
Es importante notar que, más allá de la violencia física de la que puedan ser víctimas estas mujeres, es la violencia psicológica-emocional la que dejará estas huellas tensionales en sus cuerpos. Todo tipo de violencia, al igual que toda situación que nos cree una tensión, tendrá consecuencias corporales. Está demás decir que, lamentablemente, este aspecto es frecuentemente olvidado en las terapias dirigidas a mujeres víctimas de violencia.

\section{TERAPIA A TRAVÉS DEL ARTE}

Aunque fue Margaret Naumburg la que comenzó a estudiar y poner en práctica las posibilidades curativas del arte en los años 40, el arte y su aspecto sanador ha estado presente en la historia del ser humano desde tiempos remotos. En palabras de López y Martínez: "el arte como terapia busca indagar en el conocimiento interno del ser a través de las emociones estéticas y su expresión, especialmente cuando el ejercicio de la palabra no basta o no es suficiente" (p. 13);afirmación que logra aludir tanto al ser humano primitivoy a la época infantil(en donde la palabra aun no ha sido suficientemente desarrollada),como a víctimas de violenciaintrafamiliar (en donde la dificultad para expresar lo vivido hace que la palabra sea insuficiente).Además, "el lenguaje de las imágenes, sea cual sea el elemento expresivo utilizado, sirve de ayuda, es más indirecto y proporciona mayor seguridad. Se instala en un espacio metafórico que permite nombrar a medida que se puede" (Omenat, 2006, p. 232).

Sobre esta base, en los talleres del proyecto abordamos el tema de la violencia a través de un "objeto transicional",que para Winnicott (1982) abarca una zona intermedia que incluye al juego y a la expresión artística como medios que conducen desde la subjetividad pura hacia la objetividad.De esta manera, utilizamos la pintura, el collage, la poesía, el teatro y, finalmente, la fotografía, como objetos transicionales que nos permitieron acceder indirectamente a las vivencias de estas mujeres para intentar contribuir en su reparación.

Se hace fundamental aquí la afirmación de López (2006): "En las artes visuales (...) ese soporte existe de modo más tangible y duradero que en la expresión musical o en la expresión corporal y este hecho se erige como fundamental en arteterapia" (p. 91). Esta afirmación sustenta el hecho que nuestro producto final haya sido una fotografía, ya que a través del soporte tangible del objeto y su visualización, estas mujeres pudieron reflejarse y exteriorizarse con un referente concreto. En este sentido, y a través de la misma autora, la fotografía (a diferencia del dibujo) hace posible, a través del acto de sustracción, el ir deshaciéndonos de lo accesorio hasta llegar a lo esencial. Especialmente en el caso del autorretrato fotográfico, el proceso de elección del personaje a representar, la ambientación, el vestuario y la actitud, nos obligan a hacer elecciones que reflejan aspectos esenciales del ser.

El acto de mirar el autorretrato es extremadamente significativo en la medida que se introyecta la imagen observada. Verse reflejada en esta imagen que nos 
transmite una clara visión y actitud, nos obliga a asimilar lo simbolizado y reconocerse en ésta. El autorretrato tiene esta característica única e ineludible: te obliga a enfrentarte contigo misma. Al mirarte y verte, no puedes escapar, estás presenciando lo innegable: así te ves desde afuera, así te ven los demás. Lo terapéutico se hace evidente, especialmente si para llegar a este "mirarse" te han acompañado en un clima de confianza personas que han atravesado vivencias similares. A lo anterior se suma el que te estás retratando no exactamente cómo eres, sino más bien cómo te gustaría ser. El adoptar este personaje, el realmente vivenciarlo y ponerse en sus zapatos, te ayuda a sentir cómo lo haría éste, a mirar desde su perspectiva y a aprender que si puedes interpretar a este personaje, es porque también está dentro tuyo y el hacerlo aflorar no es tan difícil como pensabas.

Finalmente, a la osadía de mirarse a una misma interpretando un rol que no es el usual, pero que en el fondo se desea, se suma el coraje necesario para dejarse fotografiar y luego exponerse a la mirada del resto (si se decide recorrer el camino hasta una exposición fotográfica final).

\section{DERECHO A LA MIRADA Y CREACIÓN PROPIAS: EL PROYECTO}

El objetivo principal de este proyecto fue intervenir creativamente en el proceso de reparación de 20 mujeres que estuvieran viviendo o hubieran vivido situaciones de violencia de género, mediante la realización de los talleres de "autoconciencia corporal" y "escritura creativa", para luego finalizar con la creación de sus autorretratos.

Junto a este objetivo, también buscábamos: formar una conciencia reflexiva que trabajara sobre la identidad de género; permitir el desarrollo de la expresión escrita como una herramienta de liberación y creación mediante dinámicas ligadas al teatro y al arte; trabajar el cuerpo para soltar tensiones y conectarse vívidamente con éste, enfocándose en el disfrute y relajación; indagar, reflexionar y expresarse creativamente sobre sus propias historias de vida; fomentar un espacio íntimo para la expresión emocional que genere los cambios y vías para el crecimiento y fortalecimiento personal; y generar espacio para la libertad de crear y creer en una mirada nueva hacia ellas mismas utilizando el autorretrato como vía principal.

Este proyecto comenzó con una convocatoria abierta en los organismos públicos del SERNAM (Servicio Nacional de la Mujer) y el Servicio de Salud Regional, que apoyaron esta iniciativa y brindaron las facilidades de contacto con los equipos especializados que trabajan la temática de violencia de género. Cada organismo propuso su participación a mujeres que cumplieran con los requisitos para formar parte del proyecto y nos derivó sus datos. Desde ese momento, estuvo en nuestras manos la selección de las 20 mujeres que serían las beneficiarias de los talleres y creación del autorretrato. Como criterios de inclusión estaban los requisitos de haber experimentado alguna situación de violencia y haber firmado el consentimiento para la exposición de su autorretrato fotográfico. De 
las 60 postulantes, elegimos a 20 basándonos en estos criterios y en la disponibilidad de tiempo de las candidatas.

Una vez efectuada la selección, las dividimos en dos grupos de 10 participantes que asistieron una vez a la semana a los dos talleres mencionados, de una hora y media de duración por sesión y separados por un pausa de 15 minutos para descansar, disfrutar de un refrigerio y compartir libremente en grupo. De esta manera, los días Lunes asistió el primer grupo de 10 participantes para comenzar cada jornada con el taller de Autoconciencia Corporal y, luego del break, continuar con el taller de Escritura Creativa. Los días Viernes asistió el segundo grupo con la misma dinámica. Ambos talleres, de tres meses de duración, estuvieron centrados en un enfoque de trabajo creativo, introspectivo y autobiográfico.

Posteriormente, utilizamos el autorretrato fotográfico como instrumento para traducir y representar la realidad, la que rodea y habita en cada una de las mujeres que participaron en esta experiencia, ejercitando la capacidad de observarse, descubrirse, reconocerse, valorarse, crearse y mostrarse a los y las demás. De esta manera, buscamos fortalecer la propia identidad y autoestima de cada mujer. El proceso de preparación de los autorretratos incluyó: la decisión del autorretrato a representar, la confección del vestuario y las pruebas correspondientes de estas prendas, la creación del maquillaje para cada caso y, finalmente, las tomas fotográficas. Esta segunda etapa tuvo una duración de dos meses.

Finalmente, culminamos con la etapa de revisión de las tomas fotográficas y la elección en conjunto con las participantes del autorretrato que se convertiría en gigantografía. Esto, junto a la etapa de producción, montaje y organización de la exposición de cierre del taller tuvo una duración de un mes.

En suma, el proyecto en su totalidad tuvo la duración de un semestre, desde el mes de Mayo del año 2011 hasta fines de Octubre del mismo año, durante el cual nos reunimos como equipo cada semana para analizar y evaluar la evolución de cada mujer y su búsqueda personal del autorretrato deseado y, de esta manera, planificar acciones en conjunto para lograr los objetivos planteados.

\section{EL CAMINO HACIA LOS AUTORRETRATOS}

Como ya se ha mencionado anteriormente, para dar vida a este proyecto elegí mostrar líneas de acción: el trabajo corporal, la palabra creativa y, finalmente, el autorretrato fotográfico. Las dos primeras líneas buscaron dar paso a la tercera, para que así cada mujer se conectara primero con su cuerpo y sus emociones, y, posteriormente, buscara dentro de sí la imagen del autorretrato deseado.

El trabajo corporal se dirigió principalmente a volver a conectar con un cuerpo violentado y, muchas veces, abusado. Sobre la teoría de Lowen, buscamos: identificar y relajar tensiones crónicas; expresar emociones de rabia, pena y dolor que, al no ser expresadas, han devenido en restricciones respiratorias y de movimiento; y, especialmente, sentir y conectar con el cuerpo para conducir a una adecuada representación del autorretrato. 
El trabajo a través de la escritura se centró en liberar lo reprimido y buscar esa capacidad creadora que todos/as tenemos y que es un indicador de salud. "Lo universal es el juego, y corresponde a la salud: facilita el crecimiento y, por lo tanto esta última; conduce a relaciones de grupo" (Winnicott, 1982, p.65). A través de la palabra y la poesía, abordadas de manera lúdica, se buscó conectar con la emoción profunda y el recuerdo doloroso, pero enfocándose principalmente en el "querer ser", en el cambio buscado y anhelado por estas mujeres.

Todo el proceso culminó en las tomas de fotografías en donde las mujeres representaron la imagen que querían expresar de sí mismas. Este fue el paso final para culminar un proceso de introspección (a través de las diferentes vivencias de los talleres), proyección (al proyectar los rasgos deseados en un personaje a interpretar) y, finalmente, introyección. En esta última fase, el autorretrato fue observado por las participantes para permitir una toma de conciencia del proceso creativo y de lo representado a través del personaje interpretado.

\section{TALLER DE AUTOCONCIENCIA CORPORAL}

Para lograr los objetivos propuestos para este taller, trabajamos con técnicas respiratorias provenientes del Yoga y con ejercicios orientales provenientes del Tai Chi y Chi Kung, disciplinas chinas. Llevamos a cabo trabajos corporales y de automasaje, ejercicios de imaginería y relajación, que junto a algunas actividades artísticas (collage y pintura), ayudaron a las mujeres a conectarse con sus cuerpos y sus emociones de manera no amenazante. La búsqueda fue de un espacio de relajación y conciencia, de poder sentir el cuerpo en su totalidad y soltarlo. Tristezas, miedos y rabias, que han causado rigideces y tensiones, dieron paso al llanto, y desde ahí, al placer de sentir-se.

En este contexto, hay algunos datos importantes de considerar. En primer lugar, la mayoría de las mujeres afirmó que era la primera vez que trabajaban sus cuerpos a través de disciplinas de este estilo y ninguna había vivido anteriormente experiencias de técnicas de relajación. Dijeron que, por primera vez, tenían la oportunidad de sentir el cuerpo no sólo como el instrumento de uso diario, sino como un vehículo de placer. Tal como me referí anteriormente a través de las afirmaciones de Lowen con respecto a que el estar vivo plenamente significa libertad de respiración y movimiento, las mujeres afirmaron percibir cambios en sus cuerpos, sentirse relajadas luego de cada sesión y disfrutar profundamente de las actividades corporales que les ofrecía el taller. Afirmaron, además, haber aprendido ejercicios que luego repetían en sus casas y manifestaron valorar la posibilidad de expresarse a través del cuerpo. 
Otro dato relevante es que al inicio del taller algunas de las mujeres reportaron sufrir dolencias crónicas, como fibromialgia y cefalea, entre otras. Durante el desarrollo del taller, aunque no se logró una remisión total de estas dolencias, sí manifestaron el alivio parcial de los síntomas a medida que progresábamos en las sesiones. El caso de una de las participantes fue el más evidente en este sentido: Sylvia sufría de una severa fibromialgia y en un principio se negó a seguir la clase y hacer los ejercicios, declarando que era incapaz de hacerlo y temía tanto al dolor como al ridículo frente al grupo. A medida que pasaron las semanas, cada vez se involucró de manera más activa en los ejercicios realizados, y manifestó que efectivamente el dolor que sentía constantemente disminuía luego de cada sesión.

En síntesis, los beneficios que conlleva el trabajo corporal ante temáticas como la de la violencia de género probaron ser múltiples, llevando al alivio sintomatológico, a la vivencia del placer corporal y a disfrutar de cuerpos menos tensos y más relajados.Las beneficiarias manifestaron un gran agrado al asistir al taller y participaron entusiastamente en el desarrollo de las actividades.

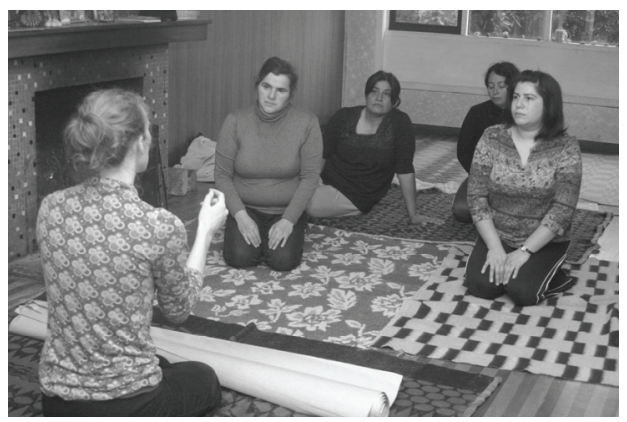

Fig. 1. Trabajando con el cuerpo y las sensaciones

\section{EXPRESIÓN A TRAVÉS DE LA POESÍA Expresión a través de la poesía}

Un cuerpo fijo que se establece en un espacio puede ser en sí la expresión de sí mismo y dice tan sólo eso. Nada dice de su alma en relación a su estado corporal. Cualquier elucubración que digamos de él será sólo eso y lo intrínseco continuará entre los vapores de lo nebuloso. Quizás, por azar podamos tocar una fibra que se transforme en una ligera brizna de expresión o, en el peor de los casos, en una descripción racional que nos remitirá a características físicas del cuerpo que no develan su particularidad ¿Qué es lo que se necesita para abrir ese cuerpo y que ese cuerpo, a su vez, se abra en su total esplendor expresivo? Por de pronto, el movimiento; el dibujo fugaz, perenne o intenso, del gesto que realiza la primera hazaña de la apertura. El ciclo ya comienza y su recorrido será la expresión de un cuerpo traduciéndose a sí mismo a través de la palabra. Desde aquí la puerta de la creación se vislumbra más allá de cualquier nebulosa.

Esta perspectiva de trabajo y apreciación de la comunicación expresiva tanto en la poesía como en el teatro, vincula todo el organismo y, como tal, permite la liberación de procesos internos difíciles o dolorosos que permanecen enclaustrados y necesitan abrirse hacia el mundo y la conciencia.

Cuando me enfrenté a la posibilidad de trabajar con mujeres que habían vivido procesos de violencia intrafamiliar, esta idea respecto a la expresión vinculada 
al cuerpo y a la palabra, me fue absolutamente necesaria para el camino hacia la creación de significaciones ligadas a un universo íntimo, pero también a un imaginario colectivo relacionado con el dolor.

En la primera reunión de reconocimiento y presentación, pude darme cuenta de la imposibilidad corporal/expresiva de las mujeres. Muchas de ellas presentaban esos rasgos de cuerpo silente, que es la imagen que he venido percibiendo a través de mis trabajos de taller no sólo con grupos violentados; sino, también, con grupos escolares y gran parte de la comunidad sin categorizaciones particulares. La expresión abierta, natural, completa es, la mayor parte de las veces, nula. ¿Cómo lograr que fluya la palabra reveladora? Concentrándonos, obviamente, en el centro de la producción del movimiento, del gesto, de la emocionalidad y de la palabra: el cuerpo. Desde este punto hacia delante, se abre una gama de opciones y posibilidades que permiten la apertura, el vaciamiento y, sobre todo, el descubrimiento de una gestualidad que permite la especificidad de la voz: su propia palabra.

En términos concretos, la tarea a desarrollar se traslada desde el cuerpo para tocar lo interno de ese cuerpo y su posterior unión con el afuera. Un círculo que va de la implosión a la explosión. Esto básicamente, resulta así: realizar un ejercicio corporal determinado para encontrar/descubrir/destrabar la emoción de un concepto trabado que al liberarse provoca la expresión exacta, verdadera, que el alma esconde (explosión). Debo aclarar que el ejercicio corporal apunta, también, a realizaciones de trabajo que involucran sólo ciertas áreas del cuerpo, como la visión y/o la audición; por ejemplo, donde la persona se relaciona con una pintura, un dibujo, un determinado sonido o música, etc. Y a partir de ahí se conecta a un movimiento físico que, finalmente, llegará a la siguiente estación: la condensación de la palabra. El resultado de ésta, su imagen corporal, su dibujo final en el papel, permite que escritura, cuerpo y movimiento florezcan en un acto creativo que tiene nombre: el nombre de cada mujer, de cada participante, como un universo expresivo plagado de sentido. (M. Vial, comunicación personal, Noviembre 15, 2011) 


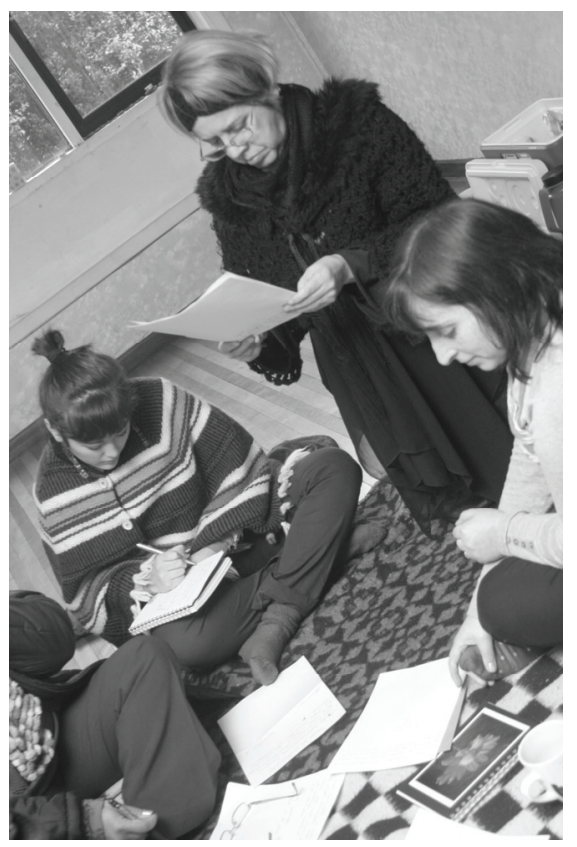

Fig. 2. Expresando a través de la palabra

\section{DESARROLLO DE LA EXPERIENCIA: EL GRUPO COMO RED DE APOYO Y EL PROCESO CREATIVO}

A medida que el grupo se conocía y afiataba, sesión a sesión, pudimos ser testigos de cómo cada participante se empezaba a sentir en confianza: la mayoría relataba sus experiencias de vida con más soltura y escuchaban atentas los comentarios y consejos del grupo. Esta confianza fue dando paso a vivencias cada vez más profundas dentro de los talleres. Así, algunas sesiones estuvieron marcadas por el llanto, el desahogo y la tristeza, y otras por la risa y la broma espontánea. Ambas, la tristeza y la risa, fueron consideradas como parte del recorrido grupal, y fundamentales para que el grupo se consolidara como red de apoyo real $\mathrm{y}$ fuerte.

Las participantes daban señales progresivas de ser cada vez más amigas,llamándose y reuniéndose en espacios fuera de los talleres. Paralelamente, pudimos ver cómo en algunas de ellas el aspecto físico fue cambiando notoriamente. Algunas mujeres que en un principio se veían más descuidadas, comenzaron a preocuparse en mayor medida por su apariencia y llegaban al taller maquilladas y vestidas con esmero. Estas señales fueron para nosotras de una alegría inmensa ya que rápidamente se comenzaba a notar un cambio en la autoestima de las mujeres. Junto a esto, comenzaron a expresar opiniones más fuertes y decidi- 
das, ya no parecían hojas al viento, sumisas ante fuerzas mayores, sino que mostraban signos de una fortaleza interna que comenzaba a manifestarse.

Luego, empezaron a aparecer los conceptos de autorretratos que cada mujer quería representar y, por tanto, estaba buscando en su interior. A medida que avanzaban las sesiones, dedicábamos cada vez un mayor tiempo al final de cada una a dilucidar el autorretrato que cada una buscaba. Así, mientras una de ellas quería verse como "patrona de fundo" (mujer ganadera), otra quería ser un hada, una mariposa, una novia, un capullo de tristeza del que se emergía fortalecida... Cada mujer nos estaba mostrando lo que buscaba en su interior y nuestro trabajo era ayudarla a representarlo lo más fielmente posible. El proceso de búsqueda de autorretrato fue acompañado con la creación de frases que representaran a cada personaje, frases que lograban dar cuenta de parte del mundo interno de cada mujer: "fui mujer estatua, pero hoy me levanto mujer sensual, llena de pasión", "la mujer serpiente muta su piel en medio de la tristeza", "libre manejo mi vida porque mujer guerrera soy", "soy una mujer que camina esperanzada", "más allá del dolor y del miedo, voy buscando la fuerza para no caer", "arquitecta de mi propio destino, busco el camino para ser feliz", "la mujer resorte que soy, se levanta más allá del dolor", entre otras.

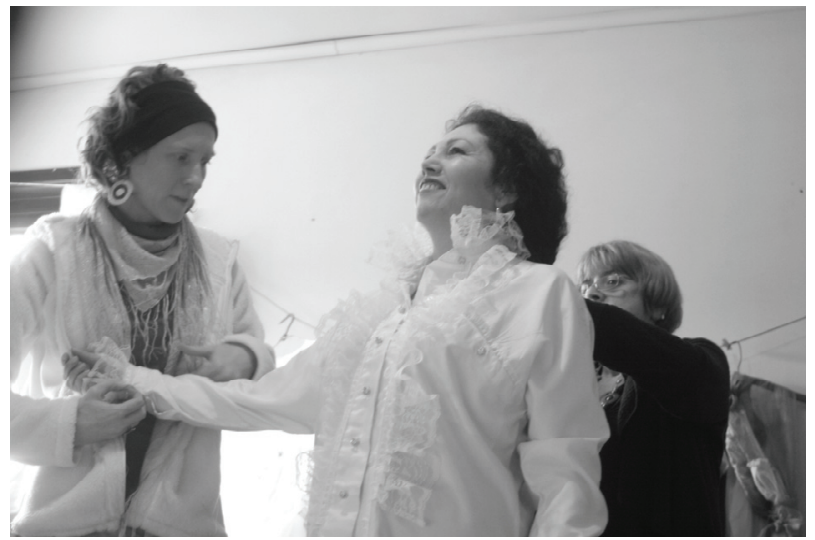

Fig. 3. Vestuario: representando al personaje

\section{AUTORRETRATOS Y EXPOSICIÓN}

Una vez que cada mujer tuvo una representación clara de lo que buscaba mostrar (y por tanto, encontrar adentro de ella), nos sumergimos en un universo de colores, telas, materiales diversos, costura, maquillaje, etc. Obtuvimos la ayuda profesional de un diseñador de vestuario teatral y de una maquilladora. De esta manera, los días de toma fotográfica de los autorretratos, todo estaba listo para que cada una de ellas pudiera encarnar este personaje ideado.

A través del nerviosismo de algunas y de una facilidad innata para la representación en otras, nos vimos envueltas hora tras hora en conceptos diversos. 
Pasamos de la fragilidad de la mariposa a la sensualidad de la mujer de burdel, de la magia de la elfa al coraje de la mujer ganadera, de la fluidez del agua a la alegría de la novia...

Una vez terminadas las tomas fotográficas de los autorretratos, nos encontramos con muchas posibilidades en nuestras manos. En esos momentos, hicimos una reunión con las mujeres en la que les mostramos sus fotografías. La alegría de mirarse representando lo que por meses habían soñado e ideado daba paso al sentirse diferente también. Junto con los agradecimientos por ambos lados, elegimos entre todas una fotografía de cada una que se convertiría en la gigantografía de la exposición.

Finalmente, llegó el gran día de la exposición del proyecto. Reunidas las mujeres, sus familias, nosotras y muchas personas interesadas en los resultados de nuestra aventura, compartimos una velada que combinó sanación y arte, todo amenizado con música en vivo, comida y bebida. Como equipo, expresamos algunas palabras acerca de nuestras vivencias en el recorrido y una de las mujeres retratadas también tuvo la oportunidad de hablar frente al público, haciendo alusión a lo vivido y a lo logrado personalmente a través de la experiencia del taller. Pudimos, entre todas, hacer un cierre de tan bella y fuerte experiencia.
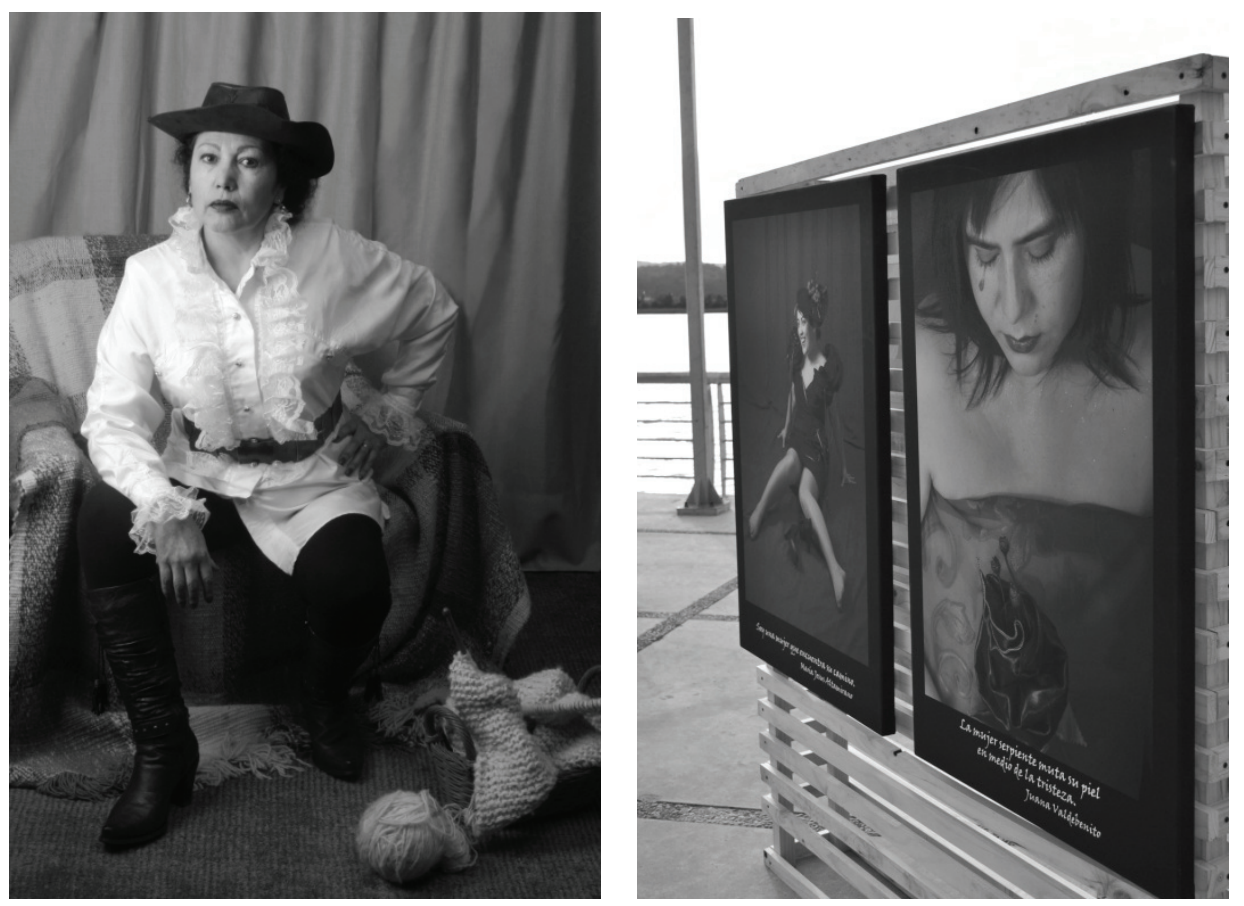

Figs. 4 y 5 . Autorretratos y exposición 


\section{ALGUNOS TESTIMONIOS}

"Cada día que pasa me voy dando cuenta de lo espléndida, fuerte, positiva, alegre y única que me siento al analizar mi vida desde que empecé a trabajar mi dolor. Me siento verdaderamente feliz, agradecida de la vida, de cada persona que estuvo en mi camino para poder sanar mi pena. Nunca las olvidaré, de cada una aprendí que la vida por todo lo malo, algo bueno te da." (María Jesús)

"Ha sido una experiencia maravillosa. Estaba llena de confusiones; sin embargo, mientras avanzaba el taller, me fui descubriendo internamente." (Patricia)

"Este taller fue completo para mí. Me recuperé de cosas del pasado y estoy muy agradecida a Dios y a las profes. Las llevo adentro del corazón y que Dios las bendiga hoy, mañana y siempre." (Nelly)

"Al escuchar, todas nos enfocábamos en el dolor de cada una. Quisiera agradecer a cada una de las integrantes y a nuestras monitoras, Maha, Vicky y Alejandra, ya que este taller me ayudó a compartir, aprender, escuchar, valerme por mí misma y, en especial, a quererme como soy.” (Yuly)

"Me ayudó a conocerme como mujer, que sí valgo y que soy muy importante." (Sylvia)

"Me sentí yo. Pude dejar ser ese yo interno. Cada una de las personas con las cuales compartí fue un aporte personal. También pienso que quienes dirigieron cada etapa del taller fueron personas muy carismáticas y comprensivas. Volvería a vivir la experiencia e instaría a que vuelvan a convocar a este tipo de talleres. Gracias." (Ximena)

"Fue extraordinario. Hubiera querido que no terminara tan pronto. Me sirvió para mi autoestima. Le doy gracias a todas las personas que me dieron buenas enseñanzas para cambiar y quererme como mujer. Me sirvió para recuperar mi matrimonio. Me sentí atractiva para mi esposo y ahora quiero superar mucho como familia. Muy agradecida por este taller." (Nibia)

"Para mí el taller fue un apoyo psicológico y emocional, ojalá se repitiera... Las tres en su forma especial te hacen sentir su apoyo con su sabiduría. Ojalá otras personas tengan la suerte que tuve yo de conocer a estas personas especiales. Vicky, Maha, Alejandra, son espectaculares." (Juana) 


\section{CONCLUSIONES}

Pensar en la mujer es pensar en mundos mútiples, diversos, creativos. Mundos llenos de historias y vidas trazadas con el empuje del afecto y, a veces, aunque no queramos, con el desafecto. Pensar en la fotografía es fijar el instante para el bienestar de la memoria; pero, también, es abrir la puerta a realidades que no conocemos, que somos incapaces de ver cotidianamente. Y pensar en mujer y fotografía es comenzar un proceso donde se fija la historia para su liberación. (Soto, Vial \& Zolezzi, 2012, Derecho a la Mirada y Creación Propias. Taller de Autorretrato, párr. 1)

Además de estas palabras que publicamos como equipo en el blog del proyecto, no puedo terminar este artículo sin compartir lo que me queda en lo personal. En primer lugar, el aprendizaje de nunca subestimar el poder transformador de ciertas experiencias. En este caso, el arte, la expresión corporal y escrita,y la fuerza del grupo se conjugan para crear una conciencia reflexiva sobre la identidad femenina, vertiéndose luego en el acto de mirarse para re-pensarse. Pero este mirarse sólo puede darse en un grupo transparente, que apoya en lugar de juzgar, que se identifica e intenta ayudar. En estas condiciones, el autorretrato se vuelve espejo y ayuda a mostrarse (a una misma y a otros), y mostrarse siempre será un acto heroico ya que se encuentra a un paso de aceptarse.

Las palabras de agradecimiento de estas mujeres hacia nosotras me conmueven profundamente, y no puedo dejar de pensar al respecto que la agradecida soy yo, ya que no siempre se es testigo y acompañante de actos heroicos como los que pudimos apreciar a través de esta experiencia.

\section{REFERENCIAS BIBLIOGRÁFICAS}

GIL RODRÍGUEZ, E. P. \& LLORET AYTER, I. (2007). La violencia de género. Barcelona, Editorial UOC.

LÓPEZ, M. (2006). "El proceso creador y sus caminos: del dibujo a la fotografía". En F. Coll Espinosa (comp.), Arteterapia: dinámicas entre creación y procesos terapéuticos (pp. 91-110). Murcia, Universidad de Murcia.

LÓPEZ, M. \& MARTÍNEZ, N. (2006). Arteterapia. Conocimiento interior a través de la expresión artística. Madrid, Ediciones Tutor.

LOWEN, A. (2010). La experiencia del placer: vivencias corporales, creatividad y bioenergética. Barcelona, Paidós Ibérica. 
MACHUCA, A. (2001). Apoyo Psicológico con Mujeres Maltratadas en su Relación de Pareja: Ilustración en un Caso Clínico. Psykhe, 10(2), 2326.Santiago, Universidad Católica de Chile.

OMENAT, M. (2006). Arteterapia con mujeres que han sufrido violencia de género: valor y uso del objeto artístico. En F. Coll Espinosa (comp.), Arteterapia: dinámicas entre creación y procesos terapéuticos (pp. 225-261). Murcia, Universidad de Murcia.

ALTO COMISIONADO DE LAS NACIONES UNIDAS PARA LOS DERECHOS HUMANOS (2000). La eliminación de la violencia contra la mujer. Resolución de la Comisión de Derechos Humanos 2000/45. Extraído de http://www.oas.org/dil/esp/1993Declaracion_sobre_la_eliminacion_de_la_violencia_contra_la_mujer.pdf

SOTO, V., VIAL, M. \& ZOLEZZI, A. (2012, 16 de febrero). Derecho a la Mirada y Creación Propias. Taller de Autorretrato. [Web log post] Recuperado de http://derechoalamirada.blogspot.com.es/2012_02_01_archive.html

WINNICOTT, D. (1982). Realidad y Juego. Barcelona, Gedisa. 